\title{
Computational study of the adsorption of molecular hydrogen on PdAg, PdAu, PtAg, and PtAu dimers
}

\author{
Piotr Matczak
}

Received: 30 July 2010/Accepted: 26 October 2010/Published online: 11 November 2010

(C) The Author(s) 2010. This article is published with open access at Springerlink.com

\begin{abstract}
The adsorption and dissociation of the $\mathrm{H}_{2}$ molecule on the $\mathrm{PdAg}, \mathrm{PdAu}$, $\mathrm{PtAg}$, and PtAu heteronuclear dimers, both isolated and deposited on carbon, were investigated by means of density functional theory. It was found that the $\mathrm{Pd}$ and $\mathrm{Pt}$ ends of the isolated dimers adsorb $\mathrm{H}_{2}$ more exoenergetically than the $\mathrm{Ag}$ and $\mathrm{Au}$ ends. The dimers were also deposited on a carbon support and it turned out that they prefer to adsorb on the support by their Pd and Pt ends rather than by the Ag and $\mathrm{Au}$ ends. The adsorption of $\mathrm{H}_{2}$ on the carbon-supported dimers is somewhat less exoenergetic than that on the isolated dimers but, after the dissociation of $\mathrm{H}_{2}$, the binding of the $\mathrm{H}$ atoms to the dimers remains stronger in the presence of the support.
\end{abstract}

Keywords Adsorption · Hydrogen - Bimetallic catalyst - Carbon support · DFT

\section{Introduction}

Palladium and platinum are of fundamental relevance in industrial catalysis [1]. They play a central role as heterogeneous catalysts in hydrogenation reactions. The addition of a second metal to palladium or platinum, that is, alloying $\mathrm{Pd}$ or $\mathrm{Pt}$, can improve the properties of the catalysts [2]. The combination of $\mathrm{Pd}$ or $\mathrm{Pt}$ with a neighboring metal such as $\mathrm{Ag}$ or $\mathrm{Au}$ leads to bimetallic catalysts that have properties different from the pure metals alone. For instance, the $\mathrm{Pt}-\mathrm{Au}$ catalyst exhibits higher selectivity toward the partial hydrogenation of compounds with two

Electronic supplementary material The online version of this article (doi:10.1007/s11144-010-0261-4) contains supplementary material, which is available to authorized users.

P. Matczak $(\bowtie)$

Department of Theoretical Chemistry, Institute of Chemistry, University of Łódź,

Tamka 12, 91-403 Lodz, Poland

e-mail: p.a.matczak@gmail.com 
$\mathrm{C}=\mathrm{C}$ bonds than pure $\mathrm{Pt}$ [3]. The adsorption of hydrogen on the catalyst is an important step in hydrogenation reactions. While $\mathrm{Pd}$ and $\mathrm{Pt}$ adsorb hydrogen molecules dissociatively, Ag and Au may be active only in the adsorption of atomic hydrogen. Hence, the mixing of $\mathrm{Pd}$ or $\mathrm{Pt}$ with $\mathrm{Ag}$ or $\mathrm{Au}$ is used for tailoring the properties of the catalyst to enhance its selectivity in hydrogenation reactions.

The bimetallic catalysts are usually deposited on oxide or carbon materials in order to maintain the bimetallic particles highly dispersed and to achieve better utilization of the noble metals $[4,5]$. Although oxide supports such as alumina and silica undisputedly dominate in the field of catalyzed hydrogenation reactions [6], carbon might also be promising, as it satisfies most of the desirable features required for a suitable support $[7,8]$. In contrast to the oxides, carbon support is considered to be relatively inert, which arises from the weak interaction between the metal atoms and the support. Despite the inertness, the catalytic properties of the bimetallic particles deposited on carbon are not governed by the metallic part entirely but, to a certain extent, the support can also affect them.

Theoretical computational methods provide a useful complement to experiments for the understanding of the adsorption of hydrogen on palladium [9-12 and references therein], platinum [13-16 and references therein], and bimetallic $\mathrm{Pd}-\mathrm{Ag}$ [17-21] and $\mathrm{Pd}-\mathrm{Au}[22,23]$ surfaces. This wealth of computational studies is contrasted by a small amount of theoretical publications in which the presence of a support was taken into account [24-28]. The Pt-H bond strength was calculated by Oudenhuijzen et al. [24] for a $\mathrm{Pt}_{4}$ cluster on $\mathrm{Na}_{2} \mathrm{O}$ and $\mathrm{F}_{2} \mathrm{O}$. Bartczak et al. [25] determined the adsorption path of hydrogen on $\mathrm{Pd} / \mathrm{MgO}$. Chen et al. studied the adsorption and diffusion of hydrogen for a $\mathrm{Pt}_{6}$ cluster saturated by $\mathrm{H}$ atoms and supported on carbon [26] and $\mathrm{MoO}_{3}$ [27] surfaces. The interaction between $\mathrm{H}_{2}$ and $\mathrm{Pt} / \gamma-\mathrm{Al}_{2} \mathrm{O}_{3}$ was examined by Ahmed et al. [28]. To the best of the author's knowledge, there is no theoretical study dealing with hydrogen molecule adsorbed on carbon-supported bimetallic catalysts.

The present work is concerned with the adsorption and dissociation of $\mathrm{H}_{2}$ molecules on the PdAg, PdAu, PtAg, and PtAu heteronuclear dimers, both isolated and deposited on a carbon support. The interaction between $\mathrm{H}_{2}$ and the dimers is investigated by means of a simple theoretical approach based on density functional theory (DFT) combined with relatively modest basis sets. Our work addresses the following issues. First, the ability of the applied theoretical approach to reproduce the experimental and/or advanced high-level theoretical data is estimated. The calculations of some molecular properties are carried out for a series of diatomic molecules containing $\mathrm{Pd}, \mathrm{Ag}, \mathrm{Pt}, \mathrm{Au}$, and $\mathrm{H}$ (the heteronuclear dimers and the metal hydrides) and then our results are compared with the available experimental and/or advanced high-level theoretical data. The assumption is made that the qualitative correctness of the applied approach is also valid for the larger systems composed of the heteronuclear dimers and hydrogen. Second, the potential energy curves of the reactions between $\mathrm{H}_{2}$ and the isolated heteronuclear dimers are calculated for low-lying electronic states in order to study the adsorption and dissociation of $\mathrm{H}_{2}$ qualitatively. In the case of the reaction between $\mathrm{H}_{2}$ and $\mathrm{PtAu}$, our results and the available high-level calculations are collated, which constitutes an additional test for our theoretical approach. Third, some preliminary results of the calculations taking 
into account the presence of a carbon support are presented. We would like to shed some light, from a theoretical point of view, on the influence of the carbon support on the adsorption and dissociation of $\mathrm{H}_{2}$ on the heteronuclear dimers.

\section{Methods}

All calculations were carried out using the BH\&H hybrid density functional. This functional makes use of a combination of the Hartree-Fock term [29] and the Slater local functional [30] to form its exchange energy part. The correlation energy part consists of the Lee-Yang-Parr nonlocal term [31]. It should be noted that, in principle, the $\mathrm{BH} \& \mathrm{H}$ functional was not intended for transition metals and therefore it has been very rarely used for systems containing such metals [32, 33]. However, our test calculations carried out for a series of diatomic molecules containing $\mathrm{Pd}, \mathrm{Ag}$, $\mathrm{Pt}$, and $\mathrm{Au}$, which will be presented and discussed in the next section, indicate that $\mathrm{BH} \& \mathrm{H}$ predicts the properties of such molecules in reasonable agreement with the experiment and the results of the advanced high-level calculations. Besides, it was reported by Waller et al. [34] that, due to some fortuitous cancellation of errors, this functional performs well for systems governed by dispersive interactions. We suspect that these interactions may be important in the case of the carbon-supported dimers.

The BH\&H functional was combined with a mixture of basis sets. The full double- $\zeta$ D95 basis set [35] was ascribed to the atoms of the adsorbed $\mathrm{H}_{2}$ molecule, whereas the Los Alamos effective core potentials (ECP) with the valence double- $\zeta$ basis set [36] was assigned to the atoms of the heteronuclear dimers. These basis sets were previously employed in the studies of the $\mathrm{H}_{2}$ dissociation on transitionmetal clusters [20, 21].

The annihilated $S^{2}$ expectation values of the Slater determinant constructed from the KS orbitals for doublets and quartets were always very close to 0.75 and 3.75 , respectively. It means that the spin contamination was negligible.

The interaction between the isolated heteronuclear dimers and the hydrogen molecule was examined using potential energy curves (PEC). The plot of the potential energy of the whole system containing $\mathrm{H}_{2}$ and a given dimer was generated as a function of one geometric parameter, namely the distance between the mass center of $\mathrm{H}_{2}$ and the $\mathrm{Ag}$ or $\mathrm{Au}$ atom of the dimer. The PEC approach was previously proposed by Cruz et al. [37] and is described in detail in the next section. This approach was also adopted in this work for the hydrogen adsorption and dissociation on the carbon-supported heteronuclear dimers.

The carbon support was modeled by means of a polycyclic aromatic hydrocarbon molecule because such a molecule provides a qualitatively correct description of some carbon materials, e.g., the graphite (0001) basal plane, within a cluster model [38]. For this purpose, the coronene molecule, $\mathrm{C}_{24} \mathrm{H}_{12}$, was selected and its $\mathrm{C}-\mathrm{C}$ bond lengths were initially set at the same value as in graphite $(1.415 \AA)$. Owing to the limited computational resources at our disposal, the carbon atoms of the coronene central hexagon were described by the D95(d)+ basis set [35], whereas the rest of the coronene molecule had the STO-3G minimal basis set [39]. The heteronuclear dimers were deposited at the center of the coronene central hexagon 


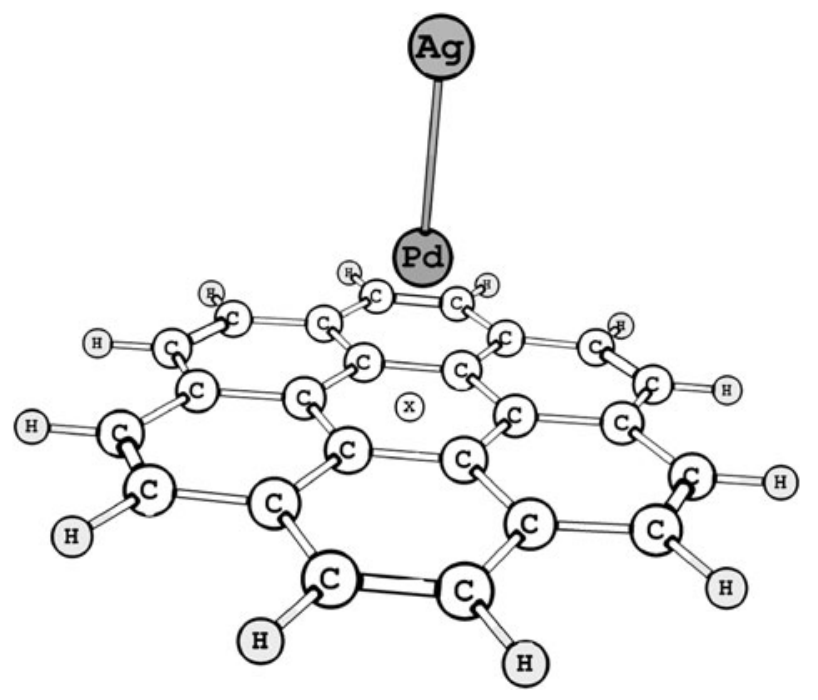

Fig. 1 Schematic representation of the cluster model representing the carbon-supported heteronuclear dimers. $\mathrm{AgPd} / \mathrm{C}$ is shown as an example. The center of the central hexagon of the coronene molecule is marked by $X$

in order to make use of symmetry and, consequently, reduce computational cost. However, this site did not turn out to be the most stable for the adsorption of the $\mathrm{Ag}_{2}$ and $\mathrm{Au}_{2}$ dimers [40] and similar behavior might be expected in the case of the heteronuclear dimers. Thus, some other sites should also be considered in the future investigations of the adsorption of the heteronuclear dimers on carbon. In our work, the perpendicular orientation of the dimer axis with respect to the coronene plane was studied (see Fig. 1). The preference of this orientation was previously observed for $\mathrm{Ag}_{2}$ and $\mathrm{Au}_{2}$ adsorbed at the center of the carbon hexagon [40].

\section{Results and discussion}

\section{Diatomic molecules}

Since DFT offers no a priori criterion for assessing the magnitude of the errors, one needs to establish it by comparison with experiments and/or advanced high-level calculations. Hence, it is neccessary to test the accuracy of DFT before performing calculations on the systems of interest. In our case, the molecular properties such as bond length, $r_{\mathrm{e}}$, dissociation energy, $D_{0}$, and vibrational frequency, $\omega_{\mathrm{e}}$, in a series of the isolated diatomic molecules containing $\mathrm{Pd}, \mathrm{Ag}, \mathrm{Pt}, \mathrm{Au}$, and $\mathrm{H}$ provided an opportunity to estimate the accuracy of the selected density functional and basis sets, namely BH\&H combined with D95 and the ECP basis set. The series of the diatomic molecules included the heteronuclear dimers (PdAg, PdAu, PtAg, PtAu), the metal hydrides $(\mathrm{PdH}, \mathrm{AgH}, \mathrm{PtH}, \mathrm{AuH})$, and, additionally, the $\mathrm{H}_{2}$ molecule. The 
Table 1 Comparison of the calculated bond length, $r_{\mathrm{e}}$, dissociation energy, $D_{0}$, and vibrational frequency, $\omega_{\mathrm{e}}$, of the PdAg, PdAu, PtAg, and PtAu dimers with available theoretical and experimental findings

\begin{tabular}{|c|c|c|c|}
\hline Molecule and method & $r_{\mathrm{e}}(\AA)$ & $\begin{array}{l}D_{0} \\
(\mathrm{kcal} / \mathrm{mol})\end{array}$ & $\begin{array}{l}\omega_{\mathrm{e}} \\
\left(\mathrm{cm}^{-1}\right)\end{array}$ \\
\hline \multicolumn{4}{|l|}{$\mathrm{PdAg}$} \\
\hline This work & 2.550 & 25.29 & 199.8 \\
\hline BP86 [20] & 2.58 & 31.36 & \\
\hline B3LYP [42] & 2.595 & 25.37 & 179.7 \\
\hline \multicolumn{4}{|l|}{$\mathrm{PdAu}$} \\
\hline This work & 2.505 & 36.88 & 205.0 \\
\hline B3LYP [42] & 2.553 & 33.67 & 179.9 \\
\hline PW91PW91 [43] & 2.51 & 42.43 & \\
\hline Experiment [44] & & 35.97 & \\
\hline \multicolumn{4}{|l|}{ PtAg } \\
\hline This work & 2.543 & 48.33 & 200.1 \\
\hline CASSCF [45] & 2.64 & 27.67 & 165 \\
\hline 4-comp-MP2 [46] & 2.530 & & 203.0 \\
\hline \multicolumn{4}{|l|}{$\mathrm{PtAu}$} \\
\hline This work & 2.510 & 51.25 & 193.6 \\
\hline CASSCF [45] & 2.60 & 32.28 & 168 \\
\hline 2-comp-RECP-MRSDCI-SO [45] & 2.574 & 52.81 & 181 \\
\hline 4-comp-MP2 [46] & 2.455 & & 210.2 \\
\hline PW91PW91 [47] & 2.47 & 58.80 & \\
\hline BPW91 [48] & 2.511 & 53.04 & \\
\hline
\end{tabular}

zero-point energy and the basis-set superposition error (BSSE) correction [41] were incorporated into the values of $D_{0}$ obtained from $\mathrm{BH} \& \mathrm{H}$.

The calculated molecular properties of the isolated heteronuclear dimers are listed in Table 1. There is only one experimental value for these dimers, and therefore our results will be compared mostly with other theoretical calculations.

For PdAg, the predicted ground state is a ${ }^{2} \Sigma^{+}$state. To the best of the author's knowledge, no high-level calculations have been carried out for this dimer so far. Our value of $D_{0}$ is almost the same as that reported in [42], while the differences in $r_{\mathrm{e}}$ and $\omega_{\mathrm{e}}$ between BH\&H and B3LYP are noticeable.

For the $\mathrm{PdAu}$ dimer, the $\mathrm{BH} \& \mathrm{H}$ functional predicts the value of $D_{0}$ in excellent agreement with the experiment. The deviation of this value from the experimental one is smaller than those of other functionals [42, 43]. Similarly to PdAg, there is a lack of the results of high-level calculations. The ${ }^{2} \Sigma^{+} \mathrm{PdAu}$ state is identified by the $\mathrm{BH} \& \mathrm{H}$ functional as the ground state.

In the case of the PtAg and PtAu dimers, their ground states correspond to a ${ }^{2} \Delta$ electronic state. The calculated $r_{\mathrm{e}}$ and $\omega_{\mathrm{e}}$ values can be compared with the fourcomponent relativistic calculations performed by Abe et al. [46]. For both dimers, the BH\&H functional yields longer $r_{\mathrm{e}}$ and lower values of $\omega_{\mathrm{e}}$ compared to those from [46]. Our calculated $D_{0}$ of PtAu is very close to the two-component relativistic result taken from [45], although this comparison should be treated with caution, as 
Table 2 Comparison of the calculated bond length, $r_{\mathrm{e}}$, dissociation energy, $D_{0}$, and vibrational frequency, $\omega_{\mathrm{e}}$, of the $\mathrm{PdH}, \mathrm{AgH}, \mathrm{PtH}$, and $\mathrm{AuH}$ hydrides and the $\mathrm{H}_{2}$ molecule with available theoretical and experimental findings

\begin{tabular}{|c|c|c|c|}
\hline Molecule and method & $r_{\mathrm{e}}(\AA)$ & $\begin{array}{l}D_{0} \\
(\mathrm{kcal} / \mathrm{mol})\end{array}$ & $\begin{array}{l}\omega_{\mathrm{e}} \\
\left(\mathrm{cm}^{-1}\right)\end{array}$ \\
\hline \multicolumn{4}{|l|}{$\mathrm{PdH}$} \\
\hline This work & 1.548 & 52.48 & 2011.6 \\
\hline SOCI [49] & 1.545 & 53.96 & 2081 \\
\hline CASSCF/ACPF [50] & 1.527 & & 2065 \\
\hline Experiment $[51,52]$ & 1.534 & 55.81 & 2036 \\
\hline \multicolumn{4}{|l|}{$\mathrm{AgH}$} \\
\hline This work & 1.637 & 49.21 & 1768.5 \\
\hline B3LYP [53] & 1.631 & & 1709 \\
\hline MRDCI [54] & 1.614 & 53.96 & 1819 \\
\hline Experiment $[55,56]$ & 1.618 & 47.56 & 1759.7 \\
\hline \multicolumn{4}{|l|}{$\mathrm{PtH}$} \\
\hline This work & 1.532 & 75.10 & 2318.1 \\
\hline BP86 [57] & 1.526 & 95.93 & 2360 \\
\hline DPT-RSPT3 [57] & 1.520 & 76.10 & 2225 \\
\hline Experiment $[58,59]$ & 1.528 & 79.33 & 2378 \\
\hline \multicolumn{4}{|l|}{$\mathrm{AuH}$} \\
\hline This work & 1.550 & 64.47 & 2164.9 \\
\hline RESC/MRMP [60] & 1.495 & 66.18 & 2412 \\
\hline 4-comp-MRSDCI(RFCA3) [61] & 1.521 & 69.87 & 2258 \\
\hline Experiment [62] & 1.524 & 68.83 & 2305.0 \\
\hline \multicolumn{4}{|l|}{$\mathrm{H}_{2}$} \\
\hline This work & 0.749 & 100.42 & 4431.4 \\
\hline Experiment [58] & 0.741 & 107.92 & 4401.2 \\
\hline
\end{tabular}

there are considerable differences in the $r_{\mathrm{e}}$ and $\omega_{\mathrm{e}}$ values obtained by the two- and four-component relativistic methods for the PtAu dimer.

Table 2 shows the molecular properties of four metal hydrides, as well as the $\mathrm{H}_{2}$ molecule. In contrast to the heteronuclear dimers, the experimental values of the properties of all the hydrides are known.

The $\mathrm{BH} \& \mathrm{H}$ results predict the following ground states: ${ }^{2} \Sigma^{+}$for $\mathrm{PdH},{ }^{1} \Sigma^{+}$for $\mathrm{AgH}$ and $\mathrm{AuH}$, and ${ }^{1} \Sigma_{\mathrm{g}}^{+}$for $\mathrm{H}_{2}$. These results are in agreement with the experiments. Obviously, our calculated values of the molecular properties are in worse correspondence with the experimental data than the results of the advanced highlevel calculations, but the deviations of our values do not exceed a few percentage points, which seems to be a reasonable compromise between accuracy and computational cost.

According to $\mathrm{BH} \& \mathrm{H}$, the ${ }^{2} \Delta$ state of $\mathrm{PtH}$ lies below the ${ }^{2} \Sigma^{+}$state, which is opposite to the experiment. Despite this disagreement, the discrepancies between the calculated molecular properties and the experimental values are not significant. In comparison with the BP86 functional result taken from [57], BH\&H shows an evident improvement in the $D_{0}$ value. 
The comparison presented above shows that the $\mathrm{BH} \& \mathrm{H}$ density functional combined with D95 and the ECP basis set provides reliable values of the molecular properties of the diatomic molecules and is suitable for the qualitative investigation of the systems containing the heteronuclear dimers and hydrogen.

\section{Reaction of $\mathrm{H}_{2}$ with heteronuclear dimers}

The adsorption and dissociation of $\mathrm{H}_{2}$ on the heteronuclear dimers were investigated using the approach proposed by Cruz et al. [37]. This approach assumed the reaction mode in which the $\mathrm{H}-\mathrm{H}$ bond was perpendicular to the axis of a given heteronuclear dimer and the mass center of $\mathrm{H}_{2}$ lay on the axis of the dimer, that is, all the atoms were in a plane. For each side of the dimer, $\mathrm{H}_{2}$ approached the dimer perpendicularly and, subsequently, was forced to go through the dimer. The reaction path was probed in a lot of points along the axis of the dimer and in each of these points the $\mathrm{H}-\mathrm{H}$ bond length was optimized, whereas the dimer bond length was set fixed and equal to the value characteristic of the isolated dimer (see Table 1). The energy, $E$, of the system containing the dimer and the adsorbed hydrogen expressed as a function of the distance, $d$, of the $\mathrm{H}_{2}$ mass center from a given atom ( $\mathrm{Ag}$ or $\mathrm{Au}$ in our case) of the dimer formed PEC. The values of $E$ were given with respect to the energy of the separated $\mathrm{H}_{2}$ and dimer.

The PEC of the reaction between $\mathrm{H}_{2}$ and $\mathrm{PdAg}$ in two low-energy electronic states is shown in Fig. 2. When the hydrogen molecule approaches the dimer by its $\mathrm{Ag}$ side, the shallow minimum of $-4.17 \mathrm{kcal} / \mathrm{mol}$ is found for $d=-2.29 \AA$. In this minimum, the hydrogen molecule exhibits the slightly stretched $\mathrm{H}-\mathrm{H}$ bond of 0.76 , $0.01 \AA$ longer than in the isolated $\mathrm{H}_{2}$ molecule. The more exoenergetic capture of the $\mathrm{H}_{2}$ molecule is observed by the Pd side of the dimer. For $d=4.33 \AA$, the energy

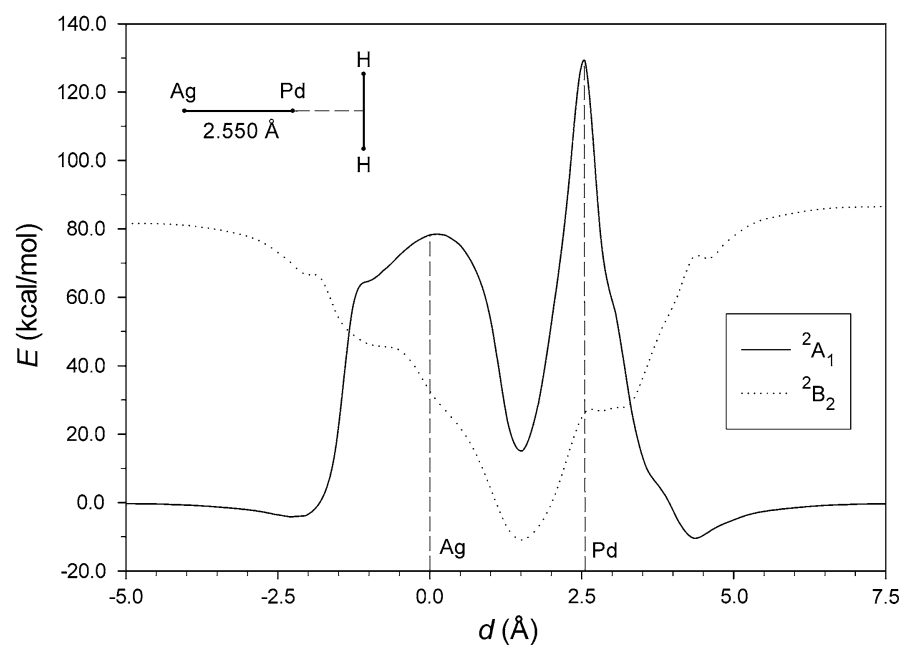

Fig. 2 Potential energy curves for the reaction of $\mathrm{H}_{2}$ with PdAg. The distance coordinate, $d$, of the mass center of $\mathrm{H}_{2}$ is measured in relation to the $\mathrm{Ag}$ atom. The energy, $E$, is reported with respect to the energy of the separated $\mathrm{H}_{2}$ and $\mathrm{PdAg}$ 
amounts to $-10.38 \mathrm{kcal} / \mathrm{mol}$ and the $\mathrm{H}-\mathrm{H}$ bond length is equal to $0.81 \AA$. Going through the dimer is accompanied by overcoming two barriers of 56.11 and $38.87 \mathrm{kcal} / \mathrm{mol}$ near the $\mathrm{Ag}$ and $\mathrm{Pd}$ atoms, respectively. The system changes its electronic state to ${ }^{2} \mathrm{~B}_{2}$ and between the metallic atoms, $d=1.53 \AA$, there is the global minimum of $-10.94 \mathrm{kcal} / \mathrm{mol}$ with the completely dissociated $\mathrm{H}_{2}$ molecule, as the $\mathrm{H}-\mathrm{H}$ bond length is equal to $2.71 \AA$.

Fig. 3 presents the PEC of the reaction of $\mathrm{H}_{2}$ with $\mathrm{PdAu}$. The hydrogen molecule combines with both metallic sides outside the dimer. The lowest-energy state of the dimer with the adsorbed $\mathrm{H}_{2}$ molecule corresponds to ${ }^{2} \mathrm{~A}_{1}$. Similarly to PdAg, the molecular capture of $\mathrm{H}_{2}$ is less exoenergetic by the Au side, $d=-2.00 \AA$ and $E=-5.56 \mathrm{kcal} / \mathrm{mol}$, than by the Pd side, $d=4.42 \AA$ and $E=-11.55 \mathrm{kcal} / \mathrm{mol}$. In both minima, the $\mathrm{H}-\mathrm{H}$ bond is lengthened to $0.78 \AA$. The $\mathrm{H}_{2}$ molecule undergoes dissociation after crossing the barriers of the height of 41.15 and $50.41 \mathrm{kcal} / \mathrm{mol}$ by the $\mathrm{Au}$ and $\mathrm{Pd}$ sides, respectively. The minimum between the metallic atoms, $d=1.25 \AA$, lies $5.94 \mathrm{kcal} / \mathrm{mol}$ higher relative to the energy of the separated $\mathrm{H}_{2}$ and $\mathrm{PdAu}$. The distance between the $\mathrm{H}$ atoms in this minimum amounts to $2.67 \AA$.

As it is seen in Fig. 4, the ends of the PtAg dimer adsorb $\mathrm{H}_{2}$ in a different manner. The Ag end is able to capture the hydrogen molecule easily with the energy of $-7.72 \mathrm{kcal} / \mathrm{mol}$ and the $\mathrm{H}-\mathrm{H}$ bond length of $0.77 \AA$. The electronic state of the $\mathrm{H}_{2}$ molecule adsorbed by the $\mathrm{Ag}$ side is ${ }^{2} \mathrm{~A}_{2}$. Then, the dissociation of $\mathrm{H}_{2}$ proceeds with the high barrier of $74.92 \mathrm{kcal} / \mathrm{mol}$ and the electronic state is changed into ${ }^{4} \mathrm{~B}_{2}$. Approaching the $\mathrm{Pt}$ side of the dimer, the hydrogen molecule also combines with the dimer in the molecular form with almost the same exoenergetic effect as on the other side, $E=-7.85 \mathrm{kcal} / \mathrm{mol}$ and $d=4.48 \AA$. However, slightly closer to the $\mathrm{Pt}$ atom for $d=3.82 \AA$, the second minimum is located with $E=-12.70 \mathrm{kcal} / \mathrm{mol}$ and the completely dissociated $\mathrm{H}_{2}$ of the $\mathrm{H}-\mathrm{H}$ bond length $1.80 \AA$. These minima

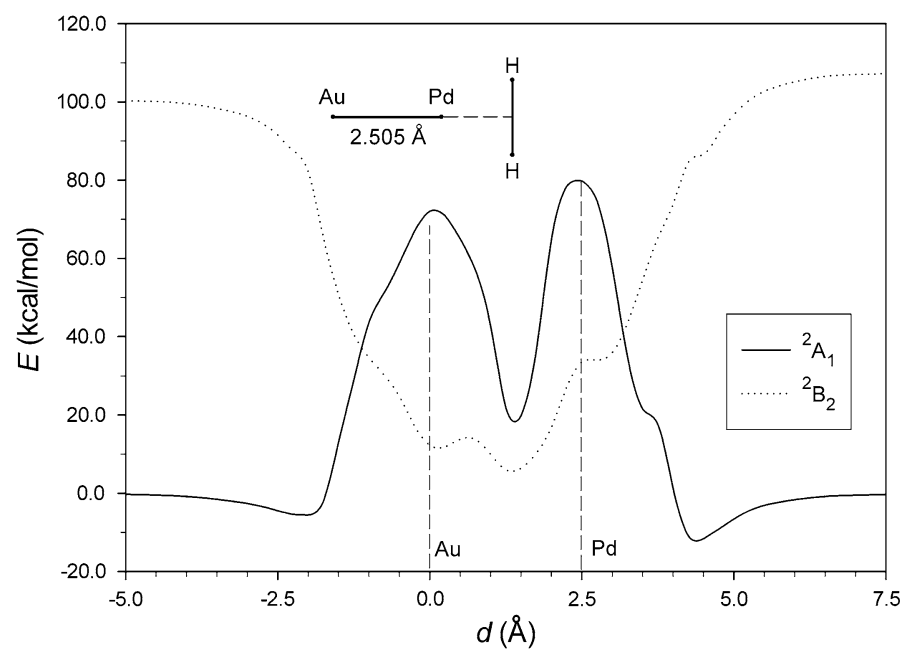

Fig. 3 Potential energy curves for the reaction of $\mathrm{H}_{2}$ with PdAu. See the caption of Fig. 2 for further notes 


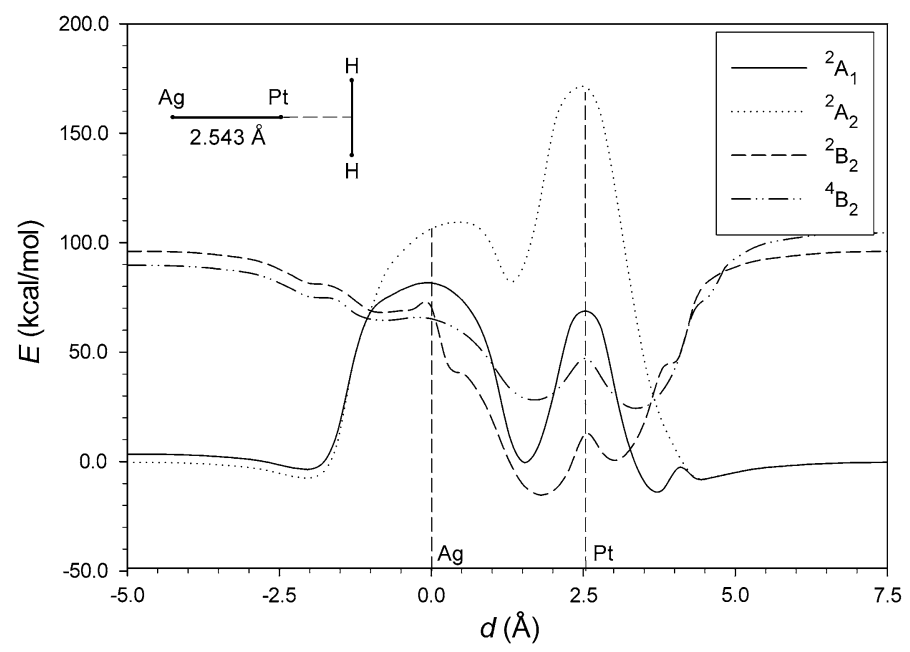

Fig. 4 Potential energy curves for the reaction of $\mathrm{H}_{2}$ with PtAg. See the caption of Fig. 2 for further notes

take place in the ${ }^{2} \mathrm{~A}_{1}$ state. Outside the dimer by the Pt side, there is also the third minimum for $d=3.05 \AA$ with the $\mathrm{H}$ atoms separated from each other by $3.06 \AA$, but the energy of this minimum is positive, $E=0.66 \mathrm{kcal} / \mathrm{mol}$, and it occurs in the ${ }^{2} \mathrm{~B}_{2}$ electronic state. These three minima are interspersed with two barriers of 4.85 and $18.39 \mathrm{kcal} / \mathrm{mol}$. In the ${ }^{2} \mathrm{~B}_{2}$ state, the barrier at the $\mathrm{Pt}$ atom requires additional $12.05 \mathrm{kcal} / \mathrm{mol}$ of energy. The global minimum is located between the metallic atoms, $d=1.78 \AA$, and its energy is $15.27 \mathrm{kcal} / \mathrm{mol}$ lower than the energy of the separated $\mathrm{H}_{2}$ and PtAg. The distance between the $\mathrm{H}$ atoms is equal to $2.90 \AA$.

The interaction between $\mathrm{H}_{2}$ and PtAu is described by the PEC from Fig. 5. The capture of $\mathrm{H}_{2}$ by the $\mathrm{Au}$ end of the PtAu dimer turns out to be more exoenergetic compared with the Ag end of PtAg. The hydrogen molecule is bound by the Au end, $d=-1.92 \AA$, with the energy of $-11.92 \mathrm{kcal} / \mathrm{mol}$ and the $\mathrm{H}-\mathrm{H}$ bond length of $0.78 \AA$. The provision of $62.20 \mathrm{kcal} / \mathrm{mol}$ of energy allows the $\mathrm{H}_{2}$ molecule to dissociate and there are changes of the electronic state from ${ }^{2} \mathrm{~A}_{2}$ to ${ }^{2} \mathrm{~A}_{1}$ and then to ${ }^{2} \mathrm{~B}_{2}$. Similarly to PtAg, the Pt end of PtAu, after the capture of $\mathrm{H}_{2}$ at the molecular level, dissociates $\mathrm{H}_{2}$ easily. Outside the dimer by the Pt end, there are three minima for $d=4.27,3.76$, and $3.01 \AA$ in the ${ }^{2} \mathrm{~A}_{2},{ }^{2} \mathrm{~A}_{1}$, and ${ }^{2} \mathrm{~B}_{2}$ states, in order. The first one corresponds to the capture of $\mathrm{H}_{2}$ with the $\mathrm{H}-\mathrm{H}$ bond length $0.83 \AA$ and $E=-17.75 \mathrm{kcal} / \mathrm{mol}$. Having crossed the barrier of $4.57 \mathrm{kcal} / \mathrm{mol}$, the $\mathrm{H}$ atoms are situated at the distance of $1.79 \AA$ from each other. Thus, the system falls into the minimum with $E=-14.87 \mathrm{kcal} / \mathrm{mol}$. The subsequent increase of the $\mathrm{H}-\mathrm{H}$ distance to $3.08 \AA$ costs $19.82 \mathrm{kcal} / \mathrm{mol}$ and the system is located in the third minimum, $E=6.04 \mathrm{kcal} / \mathrm{mol}$. The minimum inside the PtAu dimer, $d=1.71 \AA$, exhibits the energy of $-4.39 \mathrm{kcal} / \mathrm{mol}$.

For the reaction of $\mathrm{H}_{2}$ with $\mathrm{PtAu}$, the $\mathrm{BH} \& \mathrm{H}$ results can be compared with the calculations performed by means of the high-level MRCI-MR/MP2 method [37]. At the $\mathrm{BH} \& \mathrm{H}$ level of theory, the molecular captures of $\mathrm{H}_{2}$ at longer distances from the 


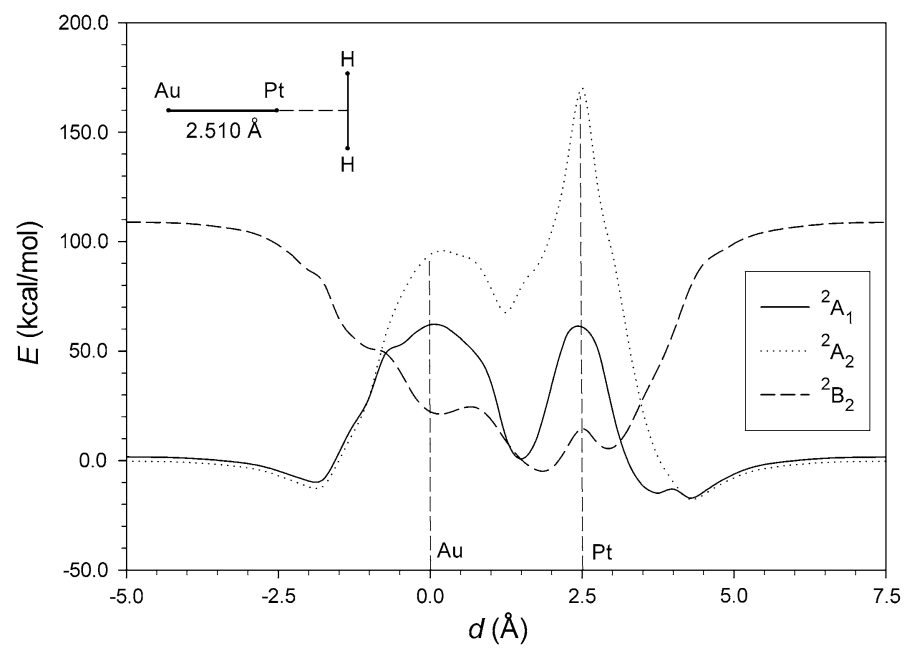

Fig. 5 Potential energy curves for the reaction of $\mathrm{H}_{2}$ with PtAu. See the caption of Fig. 2 for further notes

dimer occur in the ${ }^{2} \mathrm{~A}_{2}$ state, which is in agreement with the MRCI-MR/MP2 calculations. By the Au end of the dimer, $d=-1.80 \AA$, the $\mathrm{H}_{2}$ molecule is bound with the H-H bond length of $0.85 \AA$ and $E=-10.9 \mathrm{kcal} / \mathrm{mol}$ at the MRCI-MR/ MP2 level. BH\&H predicts that the capture of $\mathrm{H}_{2}$ takes place for $d=-1.92 \AA$ and the relaxation of the $\mathrm{H}-\mathrm{H}$ bond is smaller. For the $\mathrm{H}_{2}$ molecule approaching the $\mathrm{Pt}$ end, the MRCI-MR/MP2 minimum is found for $d=4.34 \AA$ with the $\mathrm{H}-\mathrm{H}$ bond length of $0.85 \AA$ and $E=-12.2 \mathrm{kcal} / \mathrm{mol}$. The $\mathrm{BH} \& \mathrm{H}$ findings are comparable with these results. More evident differences between BH\&H and MRCI-MR/MP2 are found for the ${ }^{2} \mathrm{~A}_{1}$ state. The high-level computations reveal that, for both dimer ends, the distances measured between the $\mathrm{H}_{2}$ mass center and the nearest end are smaller by ca. $0.2 \AA$ in the ${ }^{2} \mathrm{~A}_{1}$ state than those in the ${ }^{2} \mathrm{~A}_{2}$ state. The energies of the ${ }^{2} \mathrm{~A}_{1}$ minima are slightly more exoenergetic than those of the ${ }^{2} \mathrm{~A}_{2}$ minima. By contrast, at the $\mathrm{BH} \& \mathrm{H}$ level of theory, the ${ }^{2} \mathrm{~A}_{1}$ and ${ }^{2} \mathrm{~A}_{2}$ minima responsible for the molecular capture of $\mathrm{H}_{2}$ are located at essentially the same $d$ values and then the ${ }^{2} \mathrm{~A}_{2}$ state is energetically preferred. The above comparison shows that our simple theoretical approach reproduces the results of the advanced high-level method qualitatively. Hence, the qualitative investigation of the reactions presented earlier in this subsection seems to be meaningful. However, it should be stressed that the $\mathrm{BH} \& \mathrm{H}$ functional may suggest the incorrect energetic preference of the electronic states lying very close to each other.

To sum up this subsection, the capture of $\mathrm{H}_{2}$ at the molecular level is energetically favorable by both ends of all the investigated heteronuclear dimers. However, the Ag and $\mathrm{Au}$ ends adsorb the hydrogen molecule less exoenergetically than the $\mathrm{Pd}$ and $\mathrm{Pt}$ ends. In the case of PtAg and PtAu, their Pt ends exhibit the ability to dissociate the $\mathrm{H}_{2}$ molecule outside these dimers with the very low barriers of a few kcal/mol. For the other ends of these dimers as well as for PdAg and $\mathrm{PdAu}$, the rupture of the $\mathrm{H}-\mathrm{H}$ bond occurs while going through the metallic ends. However, large amounts of 
energy are required to overcome the barriers at these ends, and thus the $\mathrm{H}_{2}$ molecule cannot be absorbed spontaneously by all the investigated dimers. The binding of hydrogen inside the dimers is endoenergetic only for $\mathrm{PdAu}$.

\section{Heteronuclear dimers deposited on carbon}

We considered the adsorption of the heteronuclear dimers in one model site, namely in the center of carbon hexagon. The molecular axis of the dimers was perpendicular to the carbon surface and the heights of the dimers from the carbon surface were optimized along the normal line. In the course of the optimizations, the dimer bond lengths and the positions of the $\mathrm{C}$ atoms were also allowed to relax. For each dimer, the entire system containing the dimer and the support exhibited a doublet electronic state, since the energy of the system was the lowest for this state. The dimers were adsorbed on the support in two orientations. In the first one, the Pd and Pt ends of the dimers were proximate to the support, whereas, in the other one, the Ag and Au ends approached the surface. The orientations are distinguished further in the text using different expressions. For instance, the expressions $\mathrm{AgPd} / \mathrm{C}$ and $\mathrm{PdAg} / \mathrm{C}$ are used to mean that the PdAg dimer approaches the support by its $\mathrm{Pd}$ and $\mathrm{Ag}$ ends, respectively. The adsorption energy of a given dimer on carbon was calculated with respect to the energies of the isolated dimer and the support. Hence, the value of the adsorption energy includes the contributions arising from the change of the dimer bond length and the structural reorganization of the support.

The calculated geometric, energetic, and electronic parameters of the adsorption of the heteronuclear dimers on the carbon support are given in Table 3. The results indicate that the dimers exhibit very small changes of their bond lengths when adsorbed on carbon. There is no general trend in these changes: both elongations and contractions are observed for the investigated orientations of the dimers. The largest change of the dimer bond length occurs for PtAg/C, whose Pt-Ag bond is reduced by $0.044 \AA$ with respect to the bond length of the isolated PtAg.

Table 3 Calculated geometric, energetic, and electronic parameters for the adsorption of the heteronuclear dimers on carbon: dimer bond length, $r$; displacement of the nearest carbon atoms induced by the dimers, $\Delta h$; vertical distance from the carbon surface, $h$; distance from the nearest carbon atom, $d_{\mathrm{NN}}$; adsorption energy, $E$; and atomic charges from the Mulliken population analysis, $q$

\begin{tabular}{llllllll}
\hline $\mathrm{Me} 1 \mathrm{Me} 2 /$ & $\begin{array}{l}r(\mathrm{Me} 1-\mathrm{Me} 2) \\
\mathrm{C}\end{array}$ & $\begin{array}{l}\Delta h(\mathrm{C}) \\
(\AA)\end{array}$ & $\begin{array}{l}h(\mathrm{Me} 2-\mathrm{C}) \\
(\AA)\end{array}$ & $\begin{array}{l}d_{\mathrm{NN}}(\mathrm{Me} 2-\mathrm{C}) \\
(\AA)\end{array}$ & $\begin{array}{l}E(\mathrm{kcal} / \\
\mathrm{mol})\end{array}$ & $\begin{array}{l}q(\mathrm{Me} 1) \\
(e)\end{array}$ & $\begin{array}{l}q(\mathrm{Me} 2) \\
(e)\end{array}$ \\
\hline $\mathrm{AgPd} / \mathrm{C}$ & 2.570 & -0.214 & 2.128 & 2.695 & -51.29 & -0.066 & -0.222 \\
$\mathrm{PdAg} / \mathrm{C}$ & 2.542 & -0.235 & 2.197 & 2.769 & -50.35 & -0.110 & -0.381 \\
$\mathrm{AuPd} / \mathrm{C}$ & 2.533 & -0.258 & 1.930 & 2.550 & -57.49 & -0.444 & -0.066 \\
$\mathrm{PdAu} / \mathrm{C}$ & 2.503 & -0.283 & 2.270 & 2.878 & -47.76 & -0.045 & -0.262 \\
$\mathrm{AgPt} / \mathrm{C}$ & 2.532 & -0.278 & 2.314 & 2.909 & -48.05 & -0.169 & -0.210 \\
$\mathrm{PtAg} / \mathrm{C}$ & 2.499 & -0.335 & 2.391 & 2.981 & 31.90 & -0.311 & -0.927 \\
$\mathrm{AuPt} / \mathrm{C}$ & 2.506 & -0.287 & 1.895 & 2.540 & -59.86 & -0.409 & -0.067 \\
$\mathrm{PtAu} / \mathrm{C}$ & 2.513 & -0.290 & 2.129 & 2.762 & -55.78 & -0.211 & -0.179 \\
\hline
\end{tabular}

The values of $h$ and $d_{\mathrm{NN}}$ measured with respect to the dimer end adjacent to the carbon surface 
By contrast with the small changes of the dimer bond lengths, the adsorption of the dimers brings about a substantial deformation of the carbon support. However, the deformation is observed mostly for the carbon hexagon underlying the dimers. Then, the carbon atoms are depressed by the dimers (denoted as the negative sign of $\Delta h$ in Table 3). The distortion of the carbon support is greater when the dimers approach the support by their Ag and Au ends.

The adsorption of the dimers on carbon is always energetically favorable for the orientation in which the $\mathrm{Pd}$ and $\mathrm{Pt}$ ends of the dimers approach the support. In the case of $\mathrm{AuPd} / \mathrm{C}$ and $\mathrm{AuPt} / \mathrm{C}$, the adsorption energies are more exoenergetic than those of $\mathrm{AgPd} / \mathrm{C}$ and $\mathrm{AgPt} / \mathrm{C}$. Since the binding of the dimer on the support in $\mathrm{PdAg} / \mathrm{C}$ is weaker than that in $\mathrm{AgPd} / \mathrm{C}$, the height at which the $\mathrm{PdAg}$ dimer is adsorbed by its $\mathrm{Ag}$ end on carbon remains larger than that of $\mathrm{AgPd} / \mathrm{C}$. The same is true for the rest of the dimers. The endoenergetic effect of the dimer adsorption is detected only for PtAg/C. It should be stressed that in the case of $\mathrm{PdAg}$, the difference of $E$ between its two orientations on the support is less than $1 \mathrm{kcal} / \mathrm{mol}$, and therefore the energetic preference of $\mathrm{AgPd} / \mathrm{C}$ may be questionable within the framework of our simple theoretical approach. For this reason, the reaction of $\mathrm{H}_{2}$ with the carbon-supported $\mathrm{PdAg}$ will be studied in the next subsection for both orientations of the dimer.

As it can be seen in Table 3, there are charge transfers from the carbon support to all the adsorbed dimers. It is interesting to compare the Mulliken population analysis charges [63] on the atoms of the dimers adsorbed in two investigated orientations. When the orientation with the $\mathrm{Ag}$ and $\mathrm{Au}$ atoms adjacent to the support is considered, it can be noted that the $\mathrm{Ag}$ and $\mathrm{Au}$ atoms develop more negative charges than those on the Pd and Pt atoms of the dimers in the second orientation. Thus, the first orientation demonstrates stronger repulsion between the charged dimers and the electronic charge of the support. PtAg/C seems to constitute the maximum of such repulsion, as its $\mathrm{Ag}$ atom exhibits the atomic charge of $-0.927 e$.

\section{Reaction of $\mathrm{H}_{2}$ with carbon-supported heteronuclear dimers}

The adsorption and dissociation of $\mathrm{H}_{2}$ were inspected for the carbon-supported heteronuclear dimers, whose orientation with respect to the support turned out energetically preferable, that is, the orientation with the Group 10 metal end close to the support. The geometries of such dimers deposited on carbon were taken from the previous subsection. In addition, $\mathrm{PdAg} / \mathrm{C}$ was also studied for the reason given in the previous subsection. Similarly to the reactions between $\mathrm{H}_{2}$ and the isolated heteronuclear dimers, PEC was generated along the axis of a given dimer with the $\mathrm{H}-\mathrm{H}$ bond perpendicular to the dimer bond and parallel to the carbon surface. In the course of the optimization of the $\mathrm{H}-\mathrm{H}$ bond length, the positions of all the atoms of the dimer and the support were frozen, the $\mathrm{H}-\mathrm{H}$ bond was perpendicular to the dimer axis, and the $\mathrm{H}$ atoms, the dimer atoms, and two $\mathrm{C}$ atoms of the carbon hexagon lay in a plane. For the reaction of $\mathrm{H}_{2}$ with each supported dimer, PEC was determined in two spin states, that is, a doublet and a quartet; the former turned out to be of the lowest energy in most cases. The values of $E$ were given with respect to the energy of the separated $\mathrm{H}_{2}$ and carbon-supported dimer. 
The PECs of the reactions of $\mathrm{H}_{2}$ with $\mathrm{AgPd} / \mathrm{C}$ and $\mathrm{PdAg} / \mathrm{C}$ are shown in Figs. 6 and 7. The interaction between $\mathrm{H}_{2}$ and the $\mathrm{Ag}$ end of $\mathrm{AgPd} / \mathrm{C}$ is exoenergetic and the minimum that corresponds to the adsorption of $\mathrm{H}_{2}$ at the molecular level is seen for $d=7.04 \AA$ with $E=-2.41 \mathrm{kcal} / \mathrm{mol}$ and the $\mathrm{H}-\mathrm{H}$ bond length of $0.76 \AA$. The $\mathrm{H}_{2}$ dissociation barrier is very high $(84.15 \mathrm{kcal} / \mathrm{mol})$ and is accompanied by the temporary change of the electronic state to quartet around the maximum.

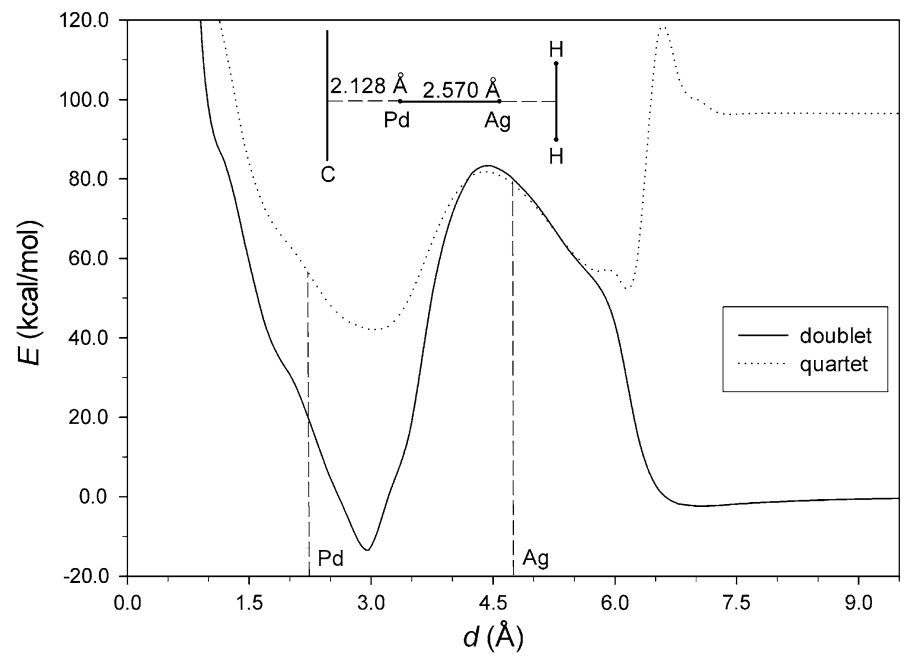

Fig. 6 Potential energy curves for the reaction of $\mathrm{H}_{2}$ with $\mathrm{AgPd} / \mathrm{C}$. The distance coordinate, $d$, of the mass center of $\mathrm{H}_{2}$ is measured in relation to the carbon surface. The energy, $E$, is reported with respect to the energy of the separated $\mathrm{H}_{2}$ and $\mathrm{AgPd} / \mathrm{C}$

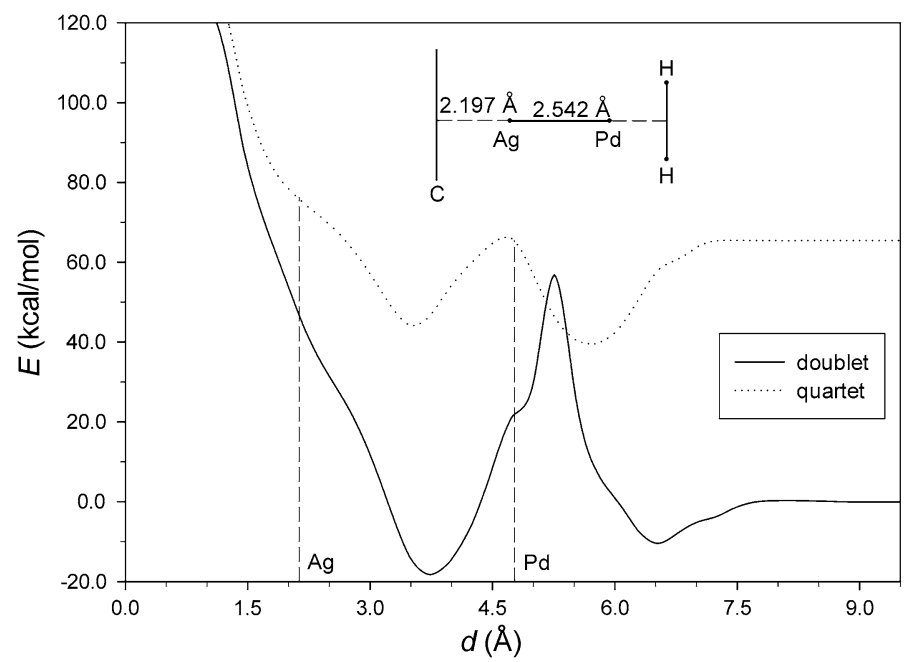

Fig. 7 Potential energy curves for the reaction of $\mathrm{H}_{2}$ with PdAg/C. See the caption of Fig. 6 for further notes 
The minimum inside the dimer, $d=2.97 \AA$, is reached with the $\mathrm{H}-\mathrm{H}$ distance equal to $2.85 \AA$ and with the energy of $-13.41 \mathrm{kcal} / \mathrm{mol}$. When the $\mathrm{H}$ atoms move closer to the $\mathrm{Pd}$ atom and then to the $\mathrm{C}$ atoms of the support, the energy increases very quickly. In the case of $\mathrm{H}_{2}$ on $\mathrm{PdAg} / \mathrm{C}$, the hydrogen molecule binds to the $\mathrm{Pd}$ end readily for $d=6.53 \AA$ with $E=-10.25 \mathrm{kcal} / \mathrm{mol}$. The $\mathrm{H}-\mathrm{H}$ bond length of $0.81 \AA$ is slightly longer than in the isolated $\mathrm{H}_{2}$ molecule. Approaching the $\mathrm{Pd}$ atom, the hydrogen molecule witnesses the presence of the barrier of $59.67 \mathrm{kcal} / \mathrm{mol}$. Similarly to $\mathrm{AgPd} / \mathrm{C}$, there are transitions of the lowest-energy electronic state from doublet to quartet and again to doublet while crossing the barrier. Inside the PdAg dimer, $d=3.73 \AA$, the global minimum exists with the $\mathrm{H}-\mathrm{H}$ distance of $2.70 \AA$ and $E=-18.26 \mathrm{kcal} / \mathrm{mol}$.

The PEC of the $\mathrm{H}_{2}$ on AuPd/C is depicted in Fig. 8. The capture of $\mathrm{H}_{2}$ with its $\mathrm{H}-\mathrm{H}$ bond length of $0.75 \AA$ and $E=-2.48 \mathrm{kcal} / \mathrm{mol}$ occurs for $d=6.89 \AA$. By the $\mathrm{Au}$ atom, there is a barrier, whose height attains $58.40 \mathrm{kcal} / \mathrm{mol}$ in the quartet state. Inside the dimer and very close to the $\mathrm{Au}$ atom, $d=4.24 \AA$, the global minimum, whose energy is equal to $-3.85 \mathrm{kcal} / \mathrm{mol}$ and whose distance between the $\mathrm{H}$ atoms is $3.31 \AA$, can be found. The subsequent nearing of the $H$ atoms to Pd requires some additional amount of energy $(5.96 \mathrm{kcal} / \mathrm{mol})$. When the energy is provided, the entire system reaches a shallow minimum for $d=3.22 \AA$. The energy of the minimum is $-0.08 \mathrm{kcal} / \mathrm{mol}$ and the $\mathrm{H}-\mathrm{H}$ distance is reduced to $2.68 \AA$.

The reaction between $\mathrm{H}_{2}$ and $\mathrm{AgPt} / \mathrm{C}$ is described by the PEC from Fig. 9. The minimum responsible for the molecular capture of $\mathrm{H}_{2}$ is located for $d=7.11 \AA$. This minimum exhibits the small exoenergetic effect of $-1.65 \mathrm{kcal} / \mathrm{mol}$ and the $\mathrm{H}-$ $\mathrm{H}$ bond length is equal to $0.76 \AA$. The dissociation of $\mathrm{H}_{2}$ entails surmounting the barrier of $75.84 \mathrm{kcal} / \mathrm{mol}$ and proceeds in the doublet spin state of the whole system. Crossing over the Ag atom decreases the energy and between the metallic atoms,

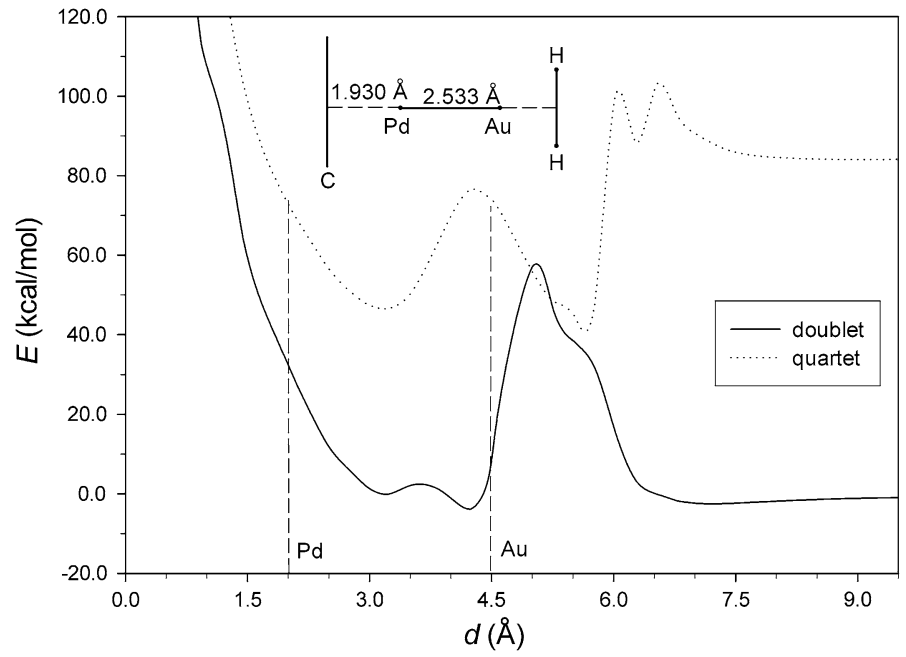

Fig. 8 Potential energy curves for the reaction of $\mathrm{H}_{2}$ with AuPd/C. See the caption of Fig. 6 for further notes 


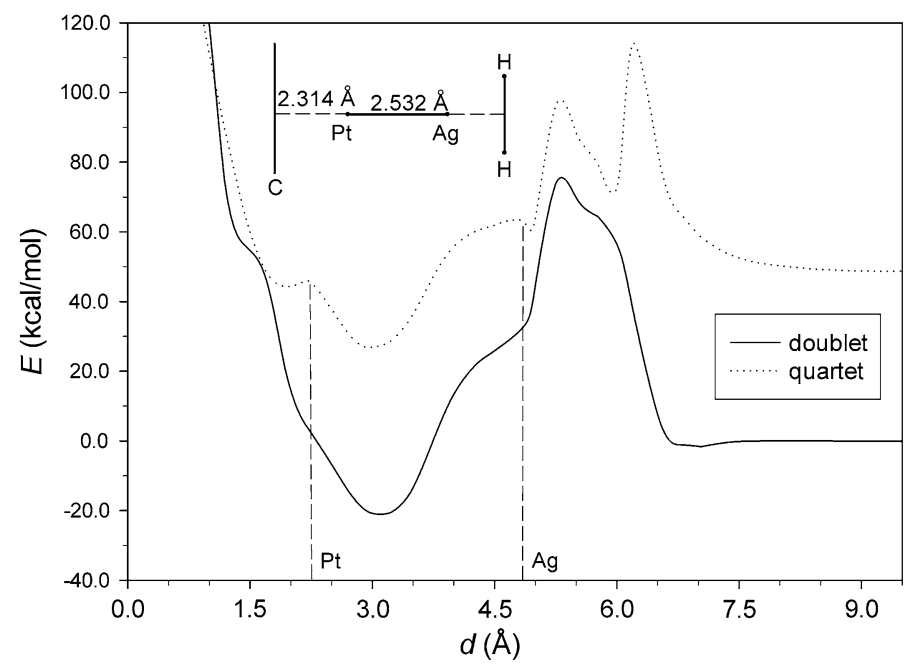

Fig. 9 Potential energy curves for the reaction of $\mathrm{H}_{2}$ with AgPt/C. See the caption of Fig. 6 for further notes

$d=3.30 \AA$, there is the global minimum that has the very exoenergetic value of $-20.60 \mathrm{kcal} / \mathrm{mol}$ with the $\mathrm{H}$ atoms separated from each other by $2.80 \AA$.

As it is shown in Fig. 10, the Au end of AuPt/C combines with the $\mathrm{H}_{2}$ molecule with $E=-5.16 \mathrm{kcal} / \mathrm{mol}$ for $d=6.58 \AA$. The bond length of the adsorbed $\mathrm{H}_{2}$ is equal to $0.77 \AA$. Crossing the barrier next to the Au end requires the energy of $53.05 \mathrm{kcal} / \mathrm{mol}$ and the transition to the quartet spin state. Inside the PtAu dimer, the minima of the doublet-state potential energy are located near each metallic atom.

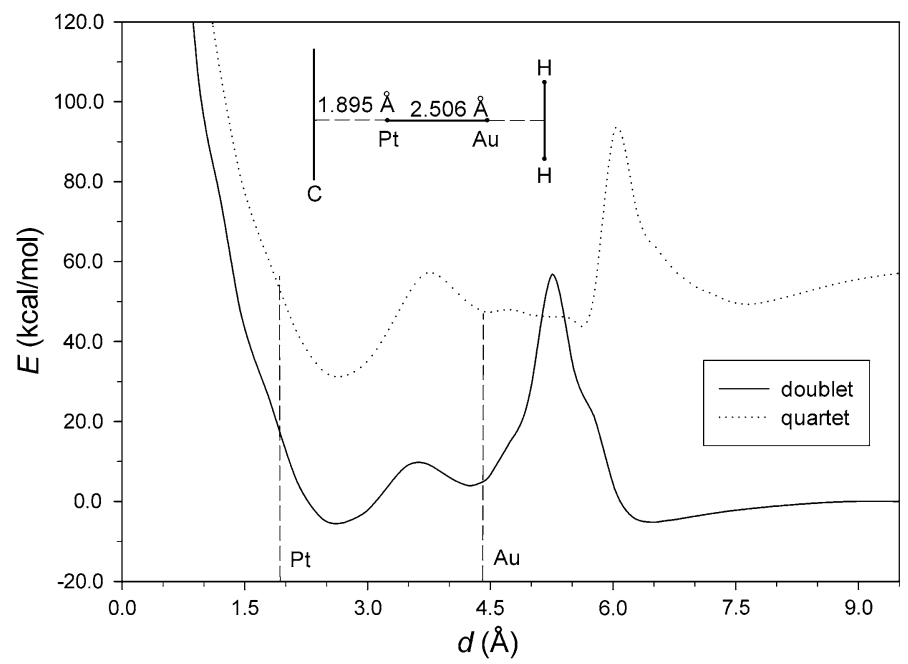

Fig. 10 Potential energy curves for the reaction of $\mathrm{H}_{2}$ with AuPt/C. See the caption of Fig. 6 for further notes 
The minimum for $d=4.24 \AA$ exhibits the endoenergetic effect, $E=3.98 \mathrm{kcal} / \mathrm{mol}$, whereas the one for $d=2.71 \AA$ corresponds to $E=-5.26 \mathrm{kcal} / \mathrm{mol}$. Both minima characterize the system with the dissociated $\mathrm{H}_{2}$ molecule (the $\mathrm{H}-\mathrm{H}$ distance is equal to 3.31 and $2.90 \AA$ ).

The comparison of the results presented in this subsection with those concerning the reactions between $\mathrm{H}_{2}$ and the isolated heteronuclear dimers allows us to determine the effect of the carbon support on the adsorption properties of the investigated heteronuclear dimers. The presence of the carbon support leads to the decrease of the exoenergetic effect of the $\mathrm{H}_{2}$ adsorption and in the case of $\mathrm{AgPt} / \mathrm{C}$ the capture of $\mathrm{H}_{2}$ exhibits the energy of only $-1.65 \mathrm{kcal} / \mathrm{mol}$. However, the decrease is by a few $\mathrm{kcal} / \mathrm{mol}$ at the most, which is in line with the inert nature of the support. The smallest decrease of the exoenergetic effect $(0.13 \mathrm{kcal} / \mathrm{mol})$ is found for $\mathrm{PdAg} /$ $\mathrm{C}$. The influence of the carbon support on the energetics of the molecular capture of $\mathrm{H}_{2}$ by the dimers may be explained qualitatively by means of the atomic charges on the isolated and carbon-supported dimers that have adsorbed the $\mathrm{H}_{2}$ molecule. The atomic charges calculated using the Mulliken population analysis are listed in Table 4. Comparing the charges of the metal atoms near the $\mathrm{H}_{2}$ molecule in the isolated and carbon-supported dimers, it can be seen that the metal atoms near the $\mathrm{H}_{2}$ molecule in the supported dimers develop more negative charges. For each pair of the dimers, that is, the isolated one and the corresponding carbon-supported one, these charges correlate with the energy of the $\mathrm{H}_{2}$ adsorption. As it was mentioned before, the carbon support delivers charge toward the dimers. During the adsorption of $\mathrm{H}_{2}$, the significant amount of this charge on the metal adjacent to the $\mathrm{H}_{2}$ molecule is still evident. This diminishes the initial charge transfer from the $\sigma$ bonding orbital of the hydrogen molecule to the metal and, consequently, leads to the weaker bonding and the decrease of the exoenergetic effect of the $\mathrm{H}_{2}$ adsorption. In the case of $\mathrm{PdAg}$ capturing $\mathrm{H}_{2}$, its $\mathrm{Pd}$ charge remains essentially the same regardless of the presence of the support (the $\mathrm{PdAg} / \mathrm{C}$ orientation), and therefore the difference in $E$ is negligible.

Table 4 Calculated geometric, energetic, and electronic parameters for the molecular capture of $\mathrm{H}_{2}$ on the isolated and carbon-supported heteronuclear dimers: distance coordinate of the $\mathrm{H}_{2}$ mass centre, $d$; $\mathrm{H}-\mathrm{H}$ bond length, $r$; energy, $E$; and atomic charges from Mulliken population analysis, $q$

\begin{tabular}{lrlcccc}
\hline $\begin{array}{l}\mathrm{Me} 1 \mathrm{Me} 2 \\
\mathrm{Me} 1 \mathrm{Me} 2 / \mathrm{C}\end{array}$ & $d(\AA)$ & $r(\mathrm{H}-\mathrm{H})(\AA)$ & $E(\mathrm{kcal} / \mathrm{mol})$ & $q(\mathrm{Me} 1)(e)$ & $q(\mathrm{Me} 2)(e)$ & $q(\mathrm{H})(e)$ \\
\hline $\mathrm{AgPd}$ & -2.29 & 0.76 & -4.17 & -0.056 & -0.055 & 0.056 \\
$\mathrm{AgPd} / \mathrm{C}$ & 7.04 & 0.76 & -2.41 & -0.141 & -0.217 & 0.050 \\
$\mathrm{PdAg}$ & 4.33 & 0.81 & -10.38 & -0.286 & 0.136 & 0.075 \\
$\mathrm{PdAg} / \mathrm{C}$ & 6.53 & 0.81 & -10.25 & -0.298 & -0.328 & 0.065 \\
$\mathrm{AuPd}$ & -2.00 & 0.78 & -5.56 & -0.476 & 0.288 & 0.094 \\
$\mathrm{AuPd} / \mathrm{C}$ & 6.89 & 0.75 & -2.48 & -0.536 & -0.007 & 0.031 \\
$\mathrm{AgPt}$ & -2.09 & 0.77 & -7.72 & 0.189 & -0.343 & 0.077 \\
$\mathrm{AgPt} / \mathrm{C}$ & 7.11 & 0.76 & -1.65 & -0.233 & -0.222 & 0.059 \\
$\mathrm{AuPt}$ & -1.92 & 0.78 & -11.92 & -0.297 & 0.087 & 0.105 \\
$\mathrm{AuPt} / \mathrm{C}$ & 6.58 & 0.77 & -5.16 & -0.614 & 0.001 & 0.077
\end{tabular}

The values of $d$ correspond to those in Figs. 2, 3, 4, 5, 6, 7, 8, 9, and 10 
Table 5 Calculated geometric, energetic, and electronic parameters for the binding of hydrogen inside the isolated and carbon-supported heteronuclear dimers: distance coordinate of the $\mathrm{H}_{2}$ mass centre, $d$; distance between the $\mathrm{H}$ atoms, $r$; energy, $E$; and atomic charges from Mulliken population analysis, $q$

\begin{tabular}{lllllll}
\hline $\mathrm{Me} 1 \mathrm{Me} 2$ & $d(\AA)$ & $r(\mathrm{H}-\mathrm{H})(\AA)$ & $E(\mathrm{kcal} / \mathrm{mol})$ & $q(\mathrm{Me} 1)(e)$ & $q(\mathrm{Me} 2)(e)$ & $q(\mathrm{H})(e)$ \\
$\mathrm{Me} 1 \mathrm{Me} 2 / \mathrm{C}$ & & & & & & \\
\hline $\mathrm{AgPd}$ & 1.53 & 2.71 & -10.94 & 0.181 & -0.246 & 0.032 \\
$\mathrm{AgPd} / \mathrm{C}$ & 2.97 & 2.85 & -13.41 & 0.244 & -0.709 & 0.065 \\
$\mathrm{PdAg} / \mathrm{C}$ & 3.73 & 2.70 & -18.26 & -0.259 & -0.319 & 0.041 \\
$\mathrm{AuPd}$ & 1.25 & 2.67 & 5.94 & -0.278 & 0.108 & 0.085 \\
$\mathrm{AuPd} / \mathrm{C}$ & 4.24 & 3.31 & -3.85 & -0.770 & 0.140 & 0.030 \\
$\mathrm{AgPt}$ & 1.78 & 2.90 & -15.27 & 0.389 & -0.492 & 0.051 \\
$\mathrm{AgPt} / \mathrm{C}$ & 3.30 & 2.80 & -20.60 & 0.082 & -0.559 & 0.063 \\
$\mathrm{AuPt}$ & 1.71 & 2.91 & -4.39 & 0.125 & -0.339 & 0.107 \\
$\mathrm{AuPt} / \mathrm{C}$ & 2.90 & 2.90 & -5.26 & -0.051 & -0.779 & 0.138 \\
\hline
\end{tabular}

The values of $d$ correspond to those in Figs. 2, 3, 4, 5, 6, 7, 8, 9, and 10

The carbon support also affects the height of the $\mathrm{H}_{2}$ dissociation barrier although, in general, the reaction mode applied in this work indicates the presence of high barriers (of a few dozen $\mathrm{kcal} / \mathrm{mol}$ ) both for the isolated and carbon-supported dimers. For $\mathrm{AgPt} / \mathrm{C}$, carbon slightly decreases the energetic barrier of $\mathrm{H}_{2}$ dissociation. In the remaining cases, the supported dimers exhibit significantly higher barriers than the corresponding isolated dimers. The presence of the high barriers is accompanied by the elongation of the $\mathrm{H}-\mathrm{H}$ bond, and thus the $\mathrm{H}_{2}$ molecule does not undergo spontaneous dissociation and absorption by all the investigated carbon-supported dimers.

The results of our calculations show that the carbon support reinforces the binding of the $\mathrm{H}$ atoms inside the heteronuclear dimers. This observation can be elucidated qualitatively in terms of the Mulliken population analysis and the calculated atomic charges for the isolated and carbon-supported dimers with the $\mathrm{H}$ atoms bound are presented in Table 5. The minima inside the dimers are usually located closer to the Group 10 metal atoms that, in the presence of the support, gain certain amounts of electronic charge. Since the $\mathrm{H}_{2}$ molecule inside the dimers is in the dissociated form and, in fact, the dimers deal with two separated $\mathrm{H}$ atoms, the additional electronic charge on Pd and Pt may be involved in the formation of the bonds with the $\mathrm{H}$ atoms. An exceptional behavior is demonstrated by $\mathrm{AuPd} / \mathrm{C}$, whose $\mathrm{Au}$ atom receives enough charge $(-0.770 e)$ to participate in the exoenergetic interaction with the $\mathrm{H}$ atoms. It is worth noting that the exoenergetic effect of $\mathrm{H}$ binding between the metallic atoms is observed for all the supported dimers.

\section{Conclusions}

This computational study investigated qualitatively the adsorption and dissociation of $\mathrm{H}_{2}$ on the PdAg, PdAu, PtAg, and PtAu heteronuclear dimers, both isolated and 
deposited on carbon. The calculations were carried out using the simple theoretical approach, namely the $\mathrm{BH} \& \mathrm{H}$ hybrid density functional together with the relatively modest basis sets. The reliability of this approach was established in a series of test calculations for the molecular properties of the isolated diatomic molecules containing $\mathrm{Pd}, \mathrm{Ag}, \mathrm{Pt}, \mathrm{Au}$, and $\mathrm{H}$ and the results were compared with the available experimental and high-level theoretical data. It turned out that our approach is suitable for the qualitative investigation of the systems composed of the abovementioned metals and hydrogen.

The adsorption and dissociation of $\mathrm{H}_{2}$ on the isolated heteronuclear dimers were studied by means of potential energy curves for the reactions in which the hydrogen molecule approached the dimers by both their ends and went through them. The H$\mathrm{H}$ bond was allowed to relax along the line perpendicular to the axis of the dimers in the course of the reactions. It was found that both ends of the isolated heteronuclear dimers capture hydrogen in its molecular form easily. However, the adsorption of the $\mathrm{H}_{2}$ molecule on the $\mathrm{Pd}$ and $\mathrm{Pt}$ ends of the dimers is more exoenergetic than that on the $\mathrm{Ag}$ and $\mathrm{Au}$ ends. The dissociation of $\mathrm{H}_{2}$ is accompanied by the presence of an energetic barrier. In most cases, the barrier is high except for PtAg and PtAu whose Pt ends are able to dissociate $\mathrm{H}_{2}$ with very small barriers.

The carbon support was modeled using the coronene molecule, $\mathrm{C}_{24} \mathrm{H}_{12}$. The heteronuclear dimers were adsorbed at the center of carbon hexagon and the axis of the dimers was perpendicular to the carbon surface. The adsorption of the dimers is exoenergetic except for the PtAg dimer that approaches the carbon support by its Ag end. In general, the adsorption of the dimers oriented by their Group 10 metal ends toward the support is energetically preferable.

The potential energy curves calculated for the reactions between $\mathrm{H}_{2}$ and the carbon-supported dimers reveal the decrease of the exoenergetic effect of $\mathrm{H}_{2}$ adsorption in the molecular form. The decrease seems rather small but, in the case of $\mathrm{AgPd} / \mathrm{C}, \mathrm{AuPd} / \mathrm{C}$, and $\mathrm{AgPt} / \mathrm{C}$, the resulting energetic effects remain only ca. $2 \mathrm{kcal} / \mathrm{mol}$ lower relatively to the energy of the separated $\mathrm{H}_{2}$ and the corresponding supported dimers. On the other hand, the carbon support brings about stronger binding of the $\mathrm{H}$ atoms inside the supported dimers compared to the isolated ones.

Acknowledgment The present work was supported by the University of Łódź research grant no. 505/ 718/R.

Open Access This article is distributed under the terms of the Creative Commons Attribution Noncommercial License which permits any noncommercial use, distribution, and reproduction in any medium, provided the original author(s) and source are credited.

\section{References}

1. Thomas JM, Thomas WJ (1997) Principles and practice of heterogeneous catalysis. VCH-Wiley, Weinheim

2. Sinfelt JH (1982) Bimetallic catalysis: discoveries, concepts and applications. Wiley, New York

3. Del Angel G, Meléndrez R, Bertin V, Dominguez JM, Marecot P, Barbier J (1993) Stud Surf Sci Catal 78:171

4. Rodriguez JA (1996) Surf Sci Rep 24:223

5. Guczi L (2005) Catal Today 101:53 
6. Alexeev OS, Gates BC (2003) Ind Eng Chem Res 42:1571

7. Rodríguez-Reinoso F (1998) Carbon 36:159

8. Auer E, Freund A, Pietsch J, Tacke T (1998) Appl Catal A Gen 173:259

9. Groß A, Scheffler M (1998) Phys Rev B 57:2493

10. Efremenko I (2001) J Mol Catal A Chem 173:19

11. Watson GW, Wells RPK, Willock DJ, Hutchings GJ (2001) J Phys Chem B 105:4889

12. Lischka M, Groß A (2002) Phys Rev B 65:075420

13. Olsen RA, Kroes GJ, Baerends EJ (1999) J Chem Phys 111:11155

14. Papoian G, Nørskov JK, Hoffmann R (2000) J Am Chem Soc 122:4129

15. Nobuhara K, Nakanishi H, Kasai H, Okiji A (2000) J Appl Phys 88:6897

16. Cruz A, Bertin V, Poulain E, Benitez JI, Castillo S (2004) J Chem Phys 120:6222

17. Løvvik OM, Olsen RA (2003) J Chem Phys 118:3268

18. González S, Neyman KM, Shaikhutdinov S, Freund H-J, Illas F (2007) J Phys Chem C 111:6852

19. Sheth PA, Neurock M, Smith CM (2005) J Phys Chem B 109:12449

20. Romanowski S, Bartczak WM, Wesołkowski R (1999) Langmuir 15:5773

21. Bartczak WM, Stawowska J (2004) Struct Chem 15:447

22. Mei D, Hansen EW, Neurock M (2003) J Phys Chem B 107:798

23. Ham HC, Hwang GS, Han J, Nam SW, Lim TH (2009) J Phys Chem C 113:12943

24. Oudenhuijzen MK, Van Bokhoven JA, Miller JT, Ramaker DE, Koningsberger DC (2005) J Am Chem Soc 127:1530

25. Bartczak WM, Stawowska J, Romanowski S (2004) Annals Pol Chem Soc 3:519

26. Chen L, Cooper AC, Pez GP, Cheng H (2007) J Phys Chem C 111:18995

27. Chen L, Cooper AC, Pez GP, Cheng H (2008) J Phys Chem C 112:1755

28. Ahmed F, Alam MK, Suzuki A, Koyama M, Tsuboi H, Hatakeyama N, Endou A, Takaba H, Del Carpio CA, Kubo M, Miyamoto A (2009) J Phys Chem C 113:15676

29. Roothan CCJ (1951) Rev Mod Phys 23:69

30. Slater JC (1974) The self-consistent field for molecules and solids: quantum theory of molecules and solids, vol 4. McGraw-Hill, New York

31. Lee C, Yang CW, Parr RG (1988) Phys Rev B 37:785

32. Armentrout PB, Koizumi H, MacKenna M (2005) J Phys Chem A 109:11365

33. Oymak H, Erkoç Ş (2010) J Phys Chem A 114:1897

34. Waller MP, Robertazzi A, Platts JA, Hibbs DE, Williams PA (2006) J Comput Chem 27:491

35. Dunning TH Jr, Hay PJ (1976) In: Schaefer HF III (ed) Modern theoretical chemistry, vol 3. Plenum, New York, p 1

36. Hay PJ, Wadt WR (1985) J Chem Phys 82:299

37. Cruz A, Poulain E, Del Angel G, Castillo S, Bertin V (1998) Int J Quantum Chem 67:399

38. Rougeau N, Teillet-Billy D, Sidis V (2006) Chem Phys Lett 431:135

39. Hehre WJ, Stewart RF, Pople JA (1969) J Chem Phys 51:2657

40. Jalkanen J-P, Halonen M, Fernández-Torre D, Laasonen K, Halonen L (2007) J Phys Chem A 111:12317

41. Boys SF, Bernardi F (1970) Mol Phys 19:553

42. Wang MY, Liu XJ, Meng J, Wu ZJ (2007) J Mol Struct Theochem 804:47

43. Sahu BR, Maofa G, Kleinman L (2003) Phys Rev B 67:115420

44. Gingerich KA (1980) Faraday Symp Chem Soc 14:109

45. Dai D, Balasubramanian K (1994) J Chem Phys 100:4401

46. Abe M, Mori S, Nakajima T, Hirao K (2005) Chem Phys 311:129

47. Yuan DW, Wang Y, Zeng Z (2005) J Chem Phys 122:114310

48. Tian WQ, Ge M, Gu F, Yamada T, Aoki Y (2006) J Phys Chem A 110:6285

49. Balasubramanian K (1990) J Chem Phys 93:8061

50. Fleig T, Marian CM (1998) J Chem Phys 108:3517

51. Malmberg C, Scullman R, Nylen P (1969) Ark Phys 39:495

52. Armentrout PA, Beauchamp JL (1989) Acc Chem Res 22:315

53. Lins JOMA, Nascimento MAC (2004) Chem Phys Lett 391:9

54. Li Y, Libermann H-P, Buenker RJ, Pichl L (2004) Chem Phys Lett 389:101

55. Birk H, Jones H (1989) Chem Phys Lett 161:27

56. Chen Y-M, Armentrout PB (1995) J Phys Chem 99:11424

57. Liu W, Franke R (2002) J Comput Chem 23:564

58. Huber KP, Herzberg G (1979) Constants of diatomic molecules. Van Nostrand Reinhold, New York 
59. Kavig B, Scullman R (1974) Phys Scr 9:33

60. Witek HA, Nakijima T, Hirao K (2000) J Chem Phys 113:8015

61. Watanabe Y, Matsuoka O (2002) J Chem Phys 116:9585

62. GMELIN Institute for Inorganic Chemistry of the Max-Planck-Society for the Advancement of Science Founded by: Gmelin L (1992) Gmelin handbook of inorganic and organometallic chemistry, 8th edn, Gold Supplement, Vol B1, System Number 62. Springer-Verlag, Heidelberg

63. Mulliken RS (1955) J Chem Phys 23:1833 